\title{
THE IMPLEMENTATION OF MALAY LANGUAGE EDUCATION POLICY AND THE LINGUISTIC LANDSCAPE IN MALAYSIA
}

\author{
Soon Chiow Thai ${ }^{1}$ \\ Center for the Promotion of Knowledge and Language, Universiti Malaysia Sabah (UMS), Malaysia. \\ (Email: soon@ums.edu.my) \\ Loi Chek Kim ${ }^{2}$ \\ Center for the Promotion of Knowledge and Language, Universiti Malaysia Sabah (UMS), Malaysia. \\ (Email: 1ck734@yahoo.com)
}

Received date: $17-12-2019$

Revised date: $27-12-2019$

Accepted date: 28-12-2019

Published date: $30-12-2019$

To cite this document: Soon, C. T., \& Loi, C. K. (2019). The Implementation of Malay Language Education Policy and The Linguistic Landscape in Malaysia. International Journal of Humanities, Philosophy and Language, 2(8), 266-277.

DOI: $10.35631 / \mathrm{ijhpl} .280020$

\begin{abstract}
This ethnographic research uses the applied linguistic landscape of Ben-Rafael (2009) to examine the choices of language practice (Spolsky, 2009) reflected through 459 Romanised names of the company on an island in Malaysia named Labuan. One of the outcomes of this study shows Malaysians are basically bilingual and about half of the names of the company are bilingual. However, the use of Malay language in naming the companies on the island is low though the Malay language is the national language of the country and the Malaysian government has implemented the Malay language education policy since independence in 1957. There are only 13\% of company names presented in pure Malay language comparing to those in pure English (45\%) and in code-mixing of Malay language and English or other languages (42\%). Besides a low percentage of using the Malay language in the company names, incorrect uses of the language were identified. The study suggests the Malaysian government specifically the local government considers the company name written in both Malay language and English instead of merely in the Malay language when it comes to approving the application of new company licenses.
\end{abstract}

Keywords: Malay Language, Language Education Policy, Linguistic landscape, Company Names

\section{Introduction}

Malaysia is a multilingual and multicultural country. Malay, Mandarin and English are used as the mother tongue of different ethnics in the country. Other languages such as the Kadanzandusun and Iban are the mother tongues of the indigenous groups in the states of Sabah and Sarawak respectively. Malaysians receive formal school education which promotes societal bilingualisms. Some of them are bilinguals of Malay language and English 
while some of them are multilinguals of Malay language, English and either Chinese language or Tamil. However, in Sebba's study, societal bilingualism refers to 'bilingualism or multilingualism at a level of social organisation beyond the individual or nuclear family' (2011, p. 445). Bilingualism may in the state or community level. A community may be 'bilingual' as a whole but the individuals may be completely monolingual or bilingual.

Malay language is selected by the authority as the only national language and official language in Malaysia. It is also the dominant medium of instruction in Malaysian education. Spolsky (2009) found that English is not only spread in Malaysian business, it is still dominating the Chinese business interactions.

Spolsky (2009) defines language choice or language practice as what people actually do and language choice may help to explain language learning. Spolsky \& Cooper (1991) introduced a Conditions model to explain the language choice on the signs (as cited in Spolsky, 2009). The conditions are: i) a 'sign-writer's skill', ii) a 'presumed reader' condition and iii) a 'symbolic value' condition (Backhaus, 2007).

What is the impact of Malay language learning in Malaysian business? Which language is more frequent used in Malaysian business, Malay language or English? The objectives of this study is to i) investigate the frequency of using Malay language and English in the business field and ii) the impact of learning of Malay language on Malaysian business. The outcomes of this study i.e. the language choice of a 'bilingual' community - the businessmen may provide valuable insights into the linguistic situation in an island named Labuan. The characteristics of language practice on the company names may reflect the long-term consequences of language and script contact.

\section{Literature Review}

The concept of language planning and linguistic landscape are reviewed in this section.

\section{Malaysian Language Planning}

Language planning is a set of ideas, laws and regulations, beliefs, and practices used to change or to stop changing the language(s) use in one or more communities. Language planning is the 'deliberate efforts to influence the behaviour of others with respect to the acquisition, structure or functional allocation of their language code' (Cooper, 1989).

The government of a polity may choose a language or languages which could serve the needs of national unification, to enhance its historical identity or to be used for a variety of sectors in modern world (Kaplan \& Baldauf, 1997).

In Malaysia, the government has chosen Malay language as the only national language and official language. The status of Malay language is explicitly enacted in Malaysian Constitution, the Article 152 - National Language and Other Language. Status planning, corpus planning and acquisition planning were designed by Malaysian government to influence the behaviour of Malaysians with respect to the acquisition, structure and functional allocation of Malay language.

\section{Status Planning}

Status planning is the external to the language(s) which related to the aspects reflecting the social issues and concerns. According to Haugen's model (1983), status planning is the issues of language selection and language implementation (Kaplan \& Baldauf, 1997). 
Language selection focuses on the development of language policy and the language items of selected language are the norm and have status within the community or country (Kaplan \& Baldauf, 1997).

In Malaysian context, the Malay language is explicitly selected as the national language. Many measures such as language policies and government agencies are established to disseminate the Malay language in the country.

\section{Corpus Planning}

As stated in Haugen's model, codification and elaboration are the issues of corpus planning (Kaplan \& Baldauf, 1997). Activities of codification include creating new lexis, modifying the old lexis and selecting the spoken and written codes.

Haugen defined language elaboration as terminological modernisation and stylistic development of the selected language. Kaplan and Baldauf (1997) added the functional development of the selected language.

The establishment of Dewan Bahasa dan Pustaka, DBP (Institute of Language and Literature) in 1956, local governments and Article 152 in the Constitution of Malaysia are for the purposes of codification and elaboration of Malay language.

According to Malaysian Investment Development Authority, there are 179 local governments responsible for approving the business premise and signboard licences (Malaysia: Investment in the services sector_ Advertising Services, n.d.). In the guideline of the Licence Department of Labuan Local Authority, one of the criteria for the application of new business licence is: Malay language is prioritised, and all the billboards or advertisement must contain Standard Malay language. That is, those new billboards will be approved only with the certification from the authorised agency $-D B P$ on the Malay language.

\section{Acquisition Planning}

Cooper agreed with Prator that language planning involves 'decisions concerning the teaching and use of language...' $(1989$, p. 31).

Malaysian Ministry of Education is the authority to design and implement 'top-down' language education policies over the years. The Razak Report introduced in 1952 was the first language education policy which endorsed the Malay language as the national language and it would serve as the medium of instruction and English was taught as the compulsory subject at all levels of national schools (Choong, 2008; Zuraidah, Farida, Ibiannaflociliana, Haijon \& Katshuhiro, 2011). English was allowed to share the status of official language till 1967 in Peninsula Malaysia, 1973 in Sabah and 1985 in Sarawak (Zuraidah et al, 2011). In addition, Malay language was recommended to be used as the main medium of instruction in all schools in the Education Act of 1961 (Choong, 2008).

The Malay language was declared as the national language in Article 152 of the Constitution of Malaysia under the National Language Act 1963/67 (Choong, 2008).

The Hussein Onn Report 1971, Mahathir Report 1979, Education Act 1996 emphasized the importance of Malay language as the language of knowledge, communication language and 
language for unity. The status of English as the second language was to be maintained (Choong, 2008).

The Educational Blueprint (2006-2010) and the Preliminary Report of the Educational Blueprint (2013-2025) recommended the Malay language to be upheld and the language proficiency of both Malay and English are to be improved through the implementation of Memartabatkan Bahasa Malaysia dan Memperkukuhkan Bahasa Inggeris or Upholding Malay language and Strengthening English respectively.

\section{Linguistic Landscape}

Landry and Bourhis brought up the concept of linguistic landscape in 1997. Linguistic landscape is 'the visibility and salience of languages on public and commercial signs in a given territory or region' (Landry \& Bourhis, 1997). Ben-Rafael (2009) defines linguistic landscape as the linguistic objects that mark the public space i.e. every space in the community or the society but not included the private propriety. This includes 'the sign and announcement located outside or inside a public institution or a private business in a given geographical location.' (Ben-Rafael, Shohamy, Amara \& Trumper-Hecht, 2006, p. 14). Linguistic landscape is able to point out the community's ways to cope with the game of symbols or signs within a complex reality. But linguistic landscape as a research tool for the study of multilingualism is still underexplored (Ben-Rafael et al., 2006).

According to Backhaus (2007), linguistic landscape study is able to show 'the common patterns of language and script use, official language policies, prevalent language attitudes, power relations between different linguistic groups, and the long-term consequences of language and script contact, among others' (p. 11). Backhaus's (2007) study found visibility of languages and scripts other than Japanese in the streets of Tokyo as a result of i) 'internationalisation' of Tokyo, ii) growing of non-Japanese residents in the city and iii) favourable attitudes towards the visibility of foreign language, particularly English.

\section{Research Methodology}

This ethnographic research aimed to study the characteristics of language choice in naming the companies by businessmen in Labuan Federal Territory. An ethnographic research is a qualitative research that describes, analyses and interprets the shared patterns of behaviors, beliefs and language of a culture-sharing group which are developed on time (Creswell, 2012).

This qualitative research was conducted to analyse the language(s) used in the corpus data. The corpus data consists of photographs of company names collected from the research site. Content analysis was applied to analyse the language choice of the business owners. The use of words on the business signs was analysed. The frequency of language(s) use, patterns of language use and the orthographic errors shown on the corpus data were also unveiled. The research site and corpus data are further discussed.

\section{Research Site}

The study was conducted on the island of Labuan. La-bu-an derives from the Malay word of laboh-an means 'anchorage' (Hall, 2007). This island is situated on the South China Sea and the north-west of Borneo Island. Labuan Island has $92 \mathrm{~km}^{2}$ and total population of Labuan is 88,100 . The ratio between the bumiputeras and the non-bumiputeras is 75,000 to 13,100 or about 6:1 in 2018 (Department of Statistics, 2019). 
On 1st of December 1912, Labuan was declared as one of the Straits Settlements by the Chartered Company (Hall, 2007). Before the island became the second federal territory in Malaysia after Kuala Lumpur in 1984, it was one of the districts of Sabah (one of the Malaysian states in North Borneo Island). In 1990, Labuan becomes an important International Offshore Financial Center (IOFC) in Malaysia.

On Labuan Island, there are only two Chinese vernacular schools which employ Mandarin as the medium of instruction for the subjects taught in the schools except for the compulsory subjects of national language - Malay language and the second language - English. The research site and corpus data are further discussed.

Besides these two schools, there are nine national secondary schools and 15 national primary schools. All these schools use the Malay language as the medium of instruction for all the subjects taught in the schools except for the second language - English.

\section{Corpus data}

The corpus data used in the present study consisted of 459 company names on Labuan Island. All Romanised company names put up in the public space at Labuan town, were collected in the form of photographs. The words used to name the companies were studied and analysed to reveal the impact of implementation of Malay language education policy on the businessmen on the island.

\section{Research Findings}

The outcome of this study showed different characteristics of language use on company names put up on the island. They are Romanised monolingual and code-mixing company names as shown in Table 1.

Table 1: Language Choice Pattern Of Company Names

\begin{tabular}{|c|c|c|}
\hline Language choice pattern & Frequency & Percentage \\
\hline Monolingual & 275 & 59.91 \\
\hline Code-mixing & 184 & 40.09 \\
\hline Total & 459 & 100 \\
\hline
\end{tabular}

The above statistics show that the company names which use monolingual is more than the code-mixing company names. The monolingual company names are subdivided into purely using Malay language, English and other languages. Furthermore, the code-mixing company names are consisted of either code-mixed of Malay language and English or code-mixed of Malay language, English and other languages. 


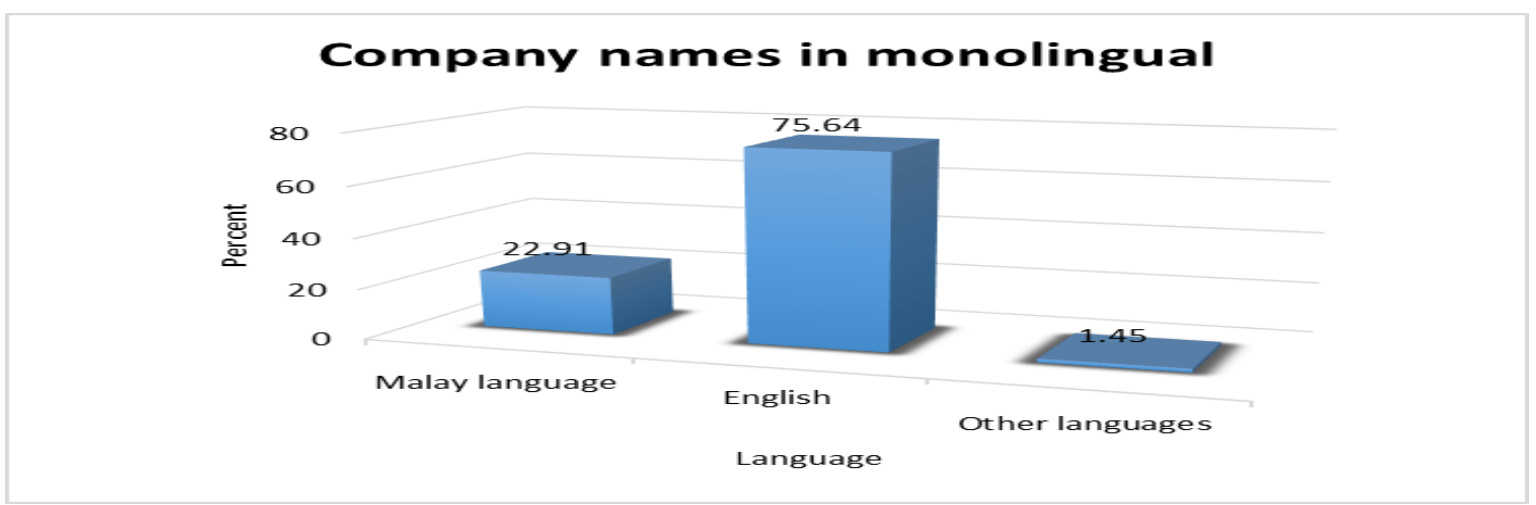

Figure 1: Number Of Company Names In Monolingual

Table 1 shows 275 company names use mono-language roman characters. 63 out of 275 company names are in Malay language, English (208 companies) and in other languages i.e. neither Malay language nor English (4 companies). The statistics indicate that three-quarter of the monolingual company names are in English (75\%). This is followed by Malay language, though having not more than $25 \%$ of the monolingual company names. The company names in other languages show the least (Figure 1). This phenomenon is further discussed below.

\section{Monolingual English Company Names}

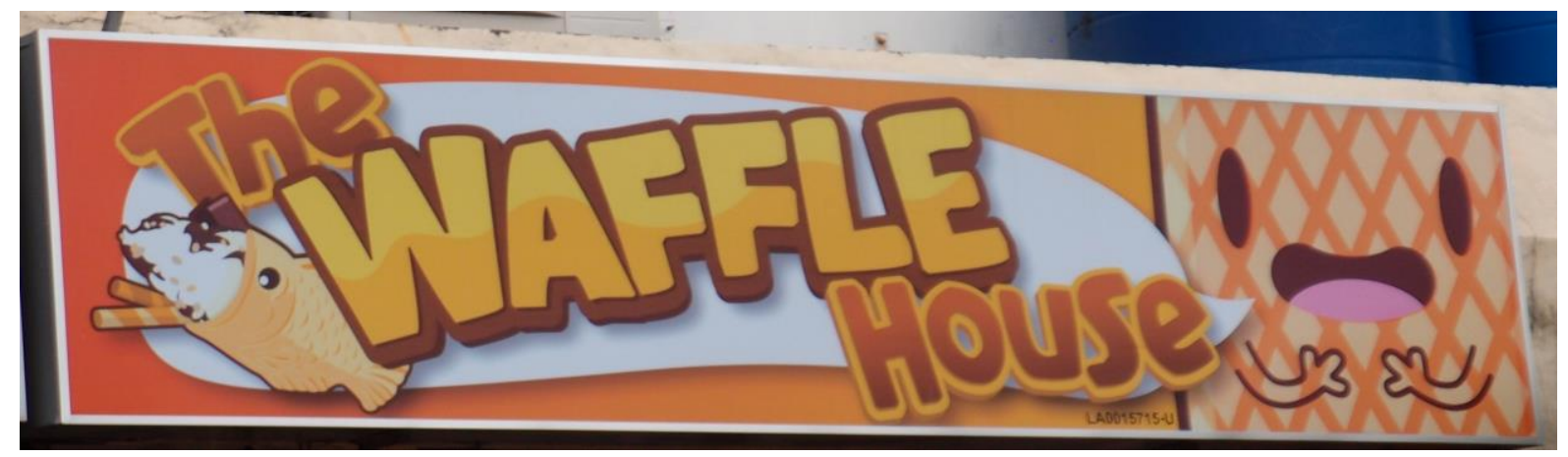

Figure 2: Monolingual Company Name In English

The business owner of the above company has chosen pure English to name his company because 'waffle' is explicitly representing the product they are selling - waffle the 'imported' food, instead of wafle in Malay language.

The statistics in Table 1 show pure English company names have the highest frequency or it can be inferred that English is the most preferred language of the businessmen on the island when it comes to naming their companies.

Malaysian education policies have explicitly stated that English is the second most important language in Malaysia. English is a compulsory subject taught in all Malaysian primary schools and secondary schools. However, it is not a compulsory pass subject in the SPM (Malaysian Certificate of Education) comparing to Malay language and History. 


\section{A L A M} ALAM HARTAWAN SDN BHD

Figure 3: Monolingual Company Name In Malay Language

The above company name is purely presented in Malay language. 'Alam Hartanawan' or literally means 'Property World'. The company name used a short form of $S d n$ Bhd instead of Sendirian Berhad.

The Article 152 in Malaysian Constitution enacted Malay language as the only national language and official language of Malaysia. Malay language is the language for inter-group communication and the symbol of nationalism.

Malay language was mandated for all the activities in the fields of media, government and most important - education. It is compulsory for students in all Malaysian schools to learn Malay language and students must gain a pass in public examinations conducted by the Ministry of Education.

Malaysian government has implemented status planning, corpus planning and acquisition planning for the national language. However, after implementing the planning in the country for more than 60 years, the number of monolingual Malay language company names on the island is only one third of the number of monolingual English company names in this study.

The outcome of this study shows the Malay language is not fully used in the field of business even though the country has been independent for 60 years.

\section{Monolingual Other Language Company Names}

As a multilingual society, many languages were used by the businessmen in Labuan to name their companies besides the national language - Malay language and the second language English.

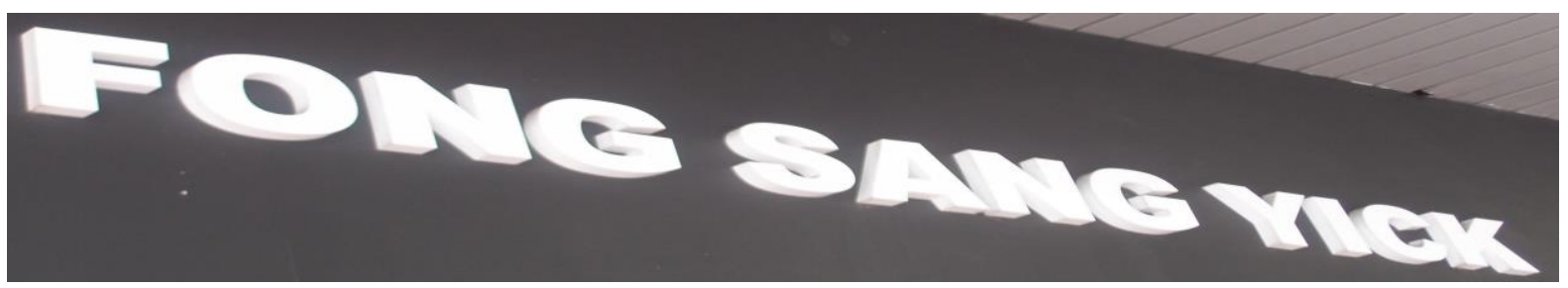

Figure 4: Monolingual Company Name In Neither Malay Language Nor English

The author studied 233 Chinese company names with Chinese lexis and found that all the company names were romanised. The transliteration or 'sound translation' method is the most productive approach practised by the Chinese businessmen to romanise their company names (Soon, Siti Aishah and Nur Shafiekah, 2017). 
Figure 4 shows a monolingual Mandarin company name using only the roman alphabets. 'Fong Sang Yick' is a Chinese name, '方生益' but the owner does not name his company by using the Chinese lexis. However, similar to other Chinese businessmen on the island, he employed the pure transliteration method i.e. he literally translated the Chinese company name by using roman alphabets based on the Dialect phonic system - the Cantonese dialect (Soon et al., 2017) and therefore the company name becomes 'Fong Sang Yick'.

\section{Code-Mixing Company Names}

The outcome of this study found two groups of company names on Labuan Island. The monolingual company names have been discussed earlier and the code-mixing company names are discussed below. Different codes are used by the company owners on the island to name their company. This method produced about 40 percent or 184 company names in the research site. There are code-mixed of English and Malay language or vice versa, Malay language, English and other language(s) some examples of code-mixing company names are discussed in the following sections.

\section{Company Name With Code-Mixing Of English And Malay Language}

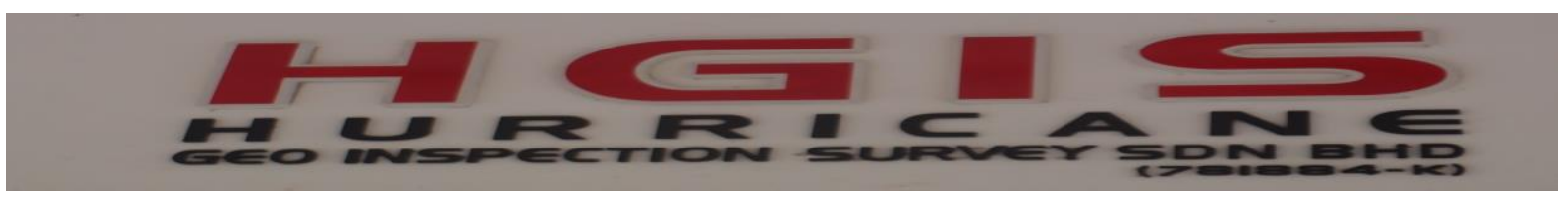

Figure 5: Code-Mixing Of English And Malay Language Company Name

The above company name in Figure 5 shows the business owner chooses English as the 'dominant' language and Malay language as the 'minor' language in naming his company. 'Hurricane', 'Geo', 'Inspection' and 'Survey' are English lexes.

The Malay lexes ' $S d n$ ' and 'Bhd' which refer to 'Sendirian' and 'Berhad' respectively are used by the business owner in naming his company. In this study, either ' $S d n$ Bhd' in short or 'Sendirian Berhad' is used to refer to 'Private Limited' in English by the businessmen on the island. None of the businessmen used 'Private Limited' to name their company as in 'Hurricane Geo Inspection Survey Private Limited' (in monolingual English).

This language choice not only showed the pattern of language use but also the power relations of language contact.

\section{Company Name With Code-Mixing Of Malay Language And English}

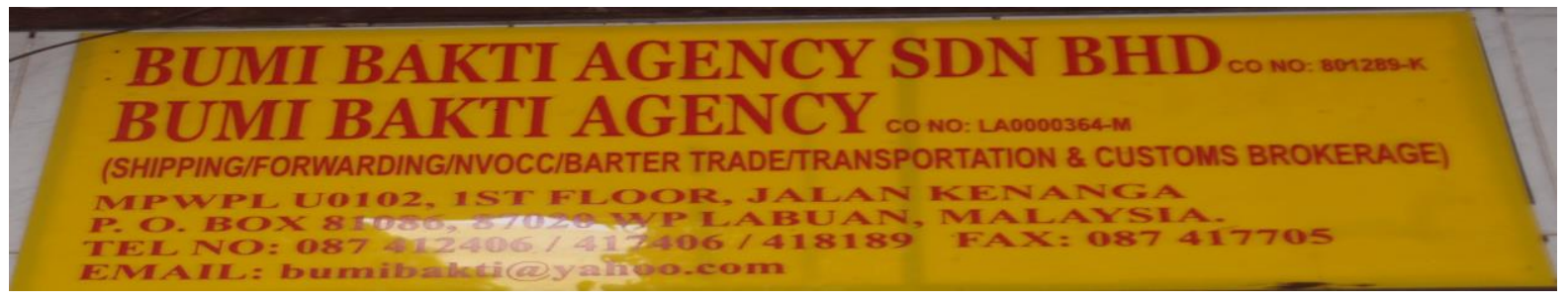

Figure 6: Code-Mixing Of Malay Language And English Company Name

Figure 6 shows a company name using the code-mix of Malay language and English. 'BUMI', 'BAKTI', 'SDN' and 'BHD' are lexis of Malay language whereas 'AGENCY' is an 
English lexis. This company name shows the use of Malay language as the dominant language with the code-mix of English.

The above company name shows the company owner has chosen the English lexis of 'agency' instead of 'agensi' in order to name the company in monolingual Malay language. The language choice of the above company name shows the consequence of language contact between Malay language and English.

\section{Company Name With Code-Mixing Of Malay Language, English And Other Language}

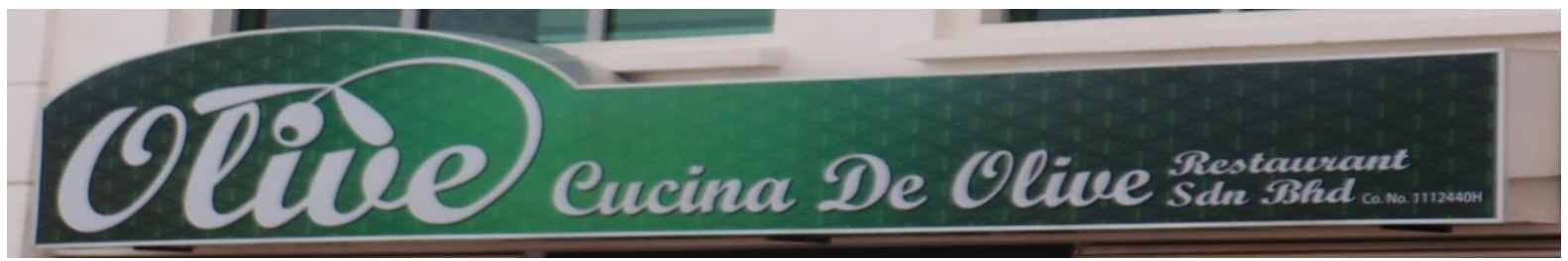

Figure 7: Code-Mixing Of Malay Language, English And Other Language

As mentioned before, Malay language is the only national language and official language, and English is the second language, other languages such as Mandarin, Tamil, KadazanDusun, Iban and other languages are free to be used in Malaysia.

The above company is named using code-mixing of three languages. The three chosen languages are Malay language, English and a foreign language i.e. the Italian language.

In the company name, 'Sdn' and 'Bhd' are the lexis of Malay language, 'restaurant' is the English lexis whereas 'Cucina', 'De' and 'Olive' are the lexis of Italian language.

As discussed in 4.2 (a), in code-mixing company name with English as 'dominant' language, and $S d n$ Bhd or Sendirian Berhad are used instead of Private Limited.

The lexis of 'Cucina' in Italian means 'kitchen' and 'De' means 'of the' in English. As a result, the literal translation in English fof the above Italian company name is 'The Olive Kitchen Restaurant Private Limited'.

The language choice of this company is named under the third condition in Spolsky \& Cooper's Conditions model (1991) i.e the 'symbolic value' condition. The 'Cucina De Olive Restaurant Sdn Bhd' is an Italian restaurant. However, the English lexis 'restaurant' is chosen instead of 'ristorante' in Italian language because the reader(s) may has/have problem in understanding the meaning of 'ristorante' comparing to 'restaurant'.

The language choice of the company owner in naming the company in Italian language has symbolically introduced to the reader(s) to what is served by the company. Through the symbolic function of the company name, the reader may easily understand the message conveyed i.e. the name of the company is 'olive restaurant' and it serves Italian food.

In summary, English is the most frequent language choice used in company signs on the island. Besides the characteristics of language choice of the businessmen on the island, this 
study also found some errors in the company names. This will be further discussed in the next section.

\section{Company Names With Error}

There are two errors found in the company names in this study. The use of English lexis of 'transportation' and 'Millennium'.

\section{The Lexis Of 'Transportation'}

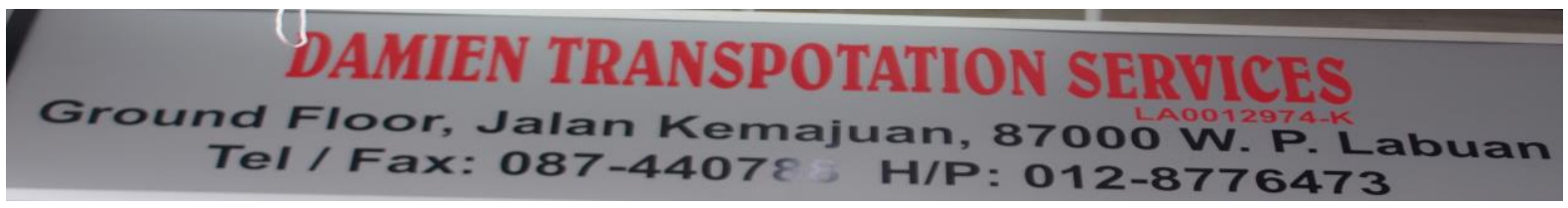

Figure 8: Company Name With Error Of 'Transportation'

\section{KUUDA LAUT TRANSPOTATION \\ ind Floor, Jalan Kemajuan, 87000 W. P. Labuan}

Tel, Fax: 087-440788 H/P : 010-4097877

Figure 9: Company Name With Error Of 'Transportation'

As shown in Figure 8 and Figure 9, both companies sign boards employ the lexis of 'transpotation' with a spelling error. These sign boards are put up at the same location to indicate that the same type of service i.e. transportation is provided.

\section{The Lexis Of 'Millennium'}

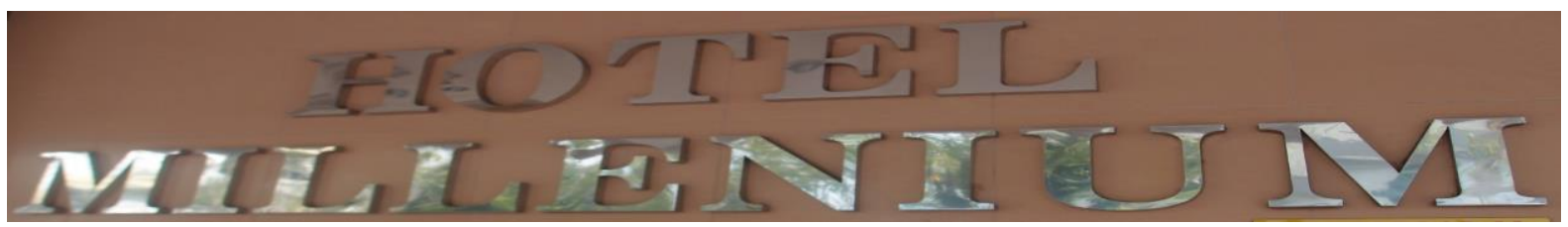

Figure 10: Company Name With Error Of 'Millennium'

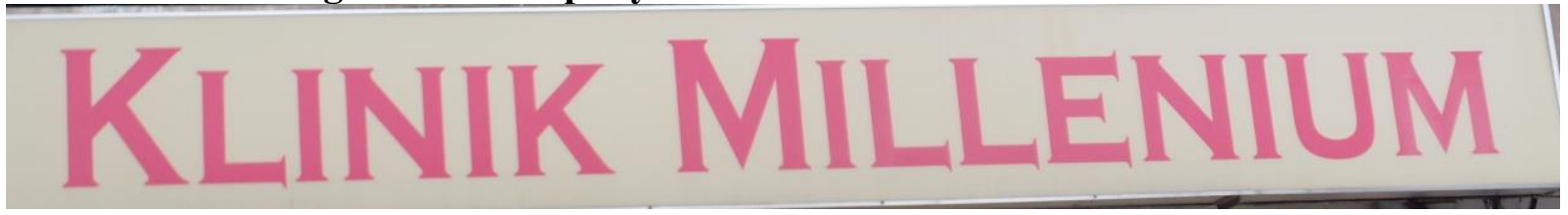

Figure 11: Company Name With Error Of 'Millennium'

In Figure 10 and 11, the company owners named their companies as 'Hotel Millenium' and 'Klinik Millenium'. The lexis of 'Hotel' was placed at the beginning of the Figure 10 and the choice of 'Klinik' in Figure 11 show both signs are in Malay language. However, the lexis 'millenium' is neither lexis of Malay language nor English. The correct orthographics of the lexis of 'millenium' in Malay language and English are 'milenium' (Kamus Dewan Online, 2017) and 'millennium' respectively.

As discussed above signs shown in Figure 8, Figure 9, Figure 10 and Figure 11 reflect the language proficiency in Malay language and English of the islanders or Malaysians. 
According to the first condition in Spolsky \& Cooper's Conditions model (1991), the 'signwriter's skill' in language choice is to choose the language that the writer knows. Therefore, the orthographic errors in these signs possibly were made by one or more than one of the following parties namely i) the business-owner, ii) the sign maker (the advertisement company making the signs) or/and iii) the officer(s) from the local authority who approved the company licences.

\section{Conclusion}

The findings of this study show that English is the most frequent language chosen by the businessmen in making their company signs on Labuan Island. English is used the most in the monolingual and bilingual business signs.

However, the above finding does not show that the islanders have high English proficiency. The orthographic errors of the lexis of 'transpotation' and 'millenium' shows a low proficiency of English and Malay language among the islanders.

In order to help to reduce the errors in the signs two suggestions are given below:

\section{To Uphold Malay Language.}

Before the company licences can be approved by the local authorities, $D B P$ is mandated by the government to certify the language choice in the company signs. Therefore, the officers of both agencies i.e. the $D B P$ and local authority are suggested to strictly follow the guidelines and criteria set before approving the business licences.

\section{To Strengthen English}

The researcher suggests the government to establish an agency for English corpus planning and acquisition planning. This agency can play an important role in strengthening the use of English in the country.

It is hope that the findings and suggestions of this study can be used as a reference by the businessmen, signboard makers and the local authorities to enhance the correct use of words on company name signboards. This attempt will indirectly contribute to upholding Malay language and to strengthen English language in the country.

\section{Reference}

Backhaus, P. (2007). Linguistic Landscapes: A Comparative Study of Urban Multilingualism in Tokyo. UK: Multilingual Matters Ltd.

Ben-Rafael, E., Shohamy, E., Amara, M.H., \& Trumper-Hecht, N. (2006). Linguistic Landscape as Symbolic Construction of the Public Space: The Case of Israel. International Journal of Multilingualism, 3 (1), 7-30.

Ben-Rafael, E. (2009). A sociological approach to the study of linguistic landscapes. In Shohamy, E., \& Gorter, D. (ed). Linguistic Landscape: Expending the scenery (pp. 40-54). New York: Routledge.

Chong, L.K. (2008). Falsafah dan Pendidikan di Malaysia: Untuk Program Perguruan Pendidikan Rendah Pengajian 4 Tahun. Kuala Lumpur: Kumpulan Budiman Sdn. Bhd.

Creswell, J.W. (2012). Educational research: planning, conducting and evaluating quantitative and qualitative research. Boston: Pearson Education Inc.

Cooper, R.L. (1989). Language Planning and Social Change. Cambridge: Cambridge University Press. 
Department of Statistics. (2019). Federal Territory of Labuan @ a Glance. Retrieve from https://www.dosm.gov.my.

Hall, M. (2007). Labuan Story: Memoirs of a Small Island near the Coast of North Borneo. Kuala Lumpur: Synergy Media.

Kamus Dewan Online. (2017). Retrieve from http://prpm.dbp.gov.my/Cari1 ?keyword= milenium

Kaplan, R.B., \& Baldauf, R.B. (1997). Language Planning From Practice to Theory. UK: Multilingual Matters Ltd.

Landry, R., \& Bourhis, R.Y. (1997). Linguistic Landscape and Ethnolinguistic Vitality: An Empirical Study. Journal of Language and Social Psychology, 1(2), 23-49.

Malaysia: Investment in the services sector_Advertising Services. (n.d.). Retrieve from www.mida.gov.my.

Sebba, M (2011). Societal Bilingualism. In Wodak, R., Johnstone, B., \& Kerswill, P. (Eds.) The SAGE Handbook of Sociolinguistics (pp. 445-459). London: SAGE Publications Ltd.

Soon, C.T., Siti Aishah Ramli, \& Nur Shafiekah Sapan. (2017). Linguistic Landscape of a multilingual community in Malaysia. Proceedings of the 8th International Conference on Language, Education, Humanities, and Innovation 2017 (pp. 13-23).

Spolsky, B. (2009). Language Management. Cambridge: Cambridge University Press.

Spolsky, B., \& Cooper, R.L. (1991). The Languages of Jerusalem. Oxford: Clarendon Press.

Zuraidah Zaaba, Farida Ibrahim Ramadan, Ibiannaflociliana Niane Anthony Anning, Haijon Gunggut, \& Umemoto, Katshuhiro. (2011). Language-in-Education Policy: A Study of Policy Adjustment Strategy in Malaysia. International Journal of Education and Information Technologies, 5(2), 157-165. 